\title{
Presenting Employee Performance- Evaluation Model using Grounded Data Theory and Fuzzy Delphi Method Case Study: An Industrial Unit Active in the Field of Polymer Disposable Accessories for Food Packaging and Pharmaceutical Serving and Packaging
}

\author{
Somayeh Sadat Mahmoudzadeh Bakhtabad ${ }^{1}$, Mohammad Taji ${ }^{2}$ \\ ${ }^{1}$ Senior Advisor Industrial Engineering, Intelligent Decision Research Group, Tehran, Iran. \\ ${ }^{2}$ Corresponding author, Department of mining Engineering, Shahrood Branch, \\ Islamic Azad University,Shahrood, Iran \\ taji@ymail.com
}

\begin{abstract}
Introduction: Given the goals and policies of human resources in the studied industrial unit concerning employee-performance evaluation (EPE), we tried to extract EPE criteria and formulate them in form of a checklist intra-organizationally using 360-degree method by relying on expert opinion - a combination of managers, consultants and experienced experts in the industry. Thus, the study dealt with providing a model in form of a checklist, periodically, for EPE.

Methods: The study was analytical, survey and statistical. The tools required to identify the criteria and indices of EPE were formulated using the grounded concept based on the results of intra-organization indices from the backgrounds and previous studies. Then, the Fuzzy Delphi method was followed by a consensus and selection of final criteria.
\end{abstract}

Results: The final checklist of performance evaluation was formulated in general and specialized sections with 17 general criteria and 4 specialized criteria. Then, it was implemented for a sample of 164 employees, which had a good reliability with Cronbach's alpha coefficient $95.2 \%$ according to the statistical analyses.

Keywords: Performance Evaluation, Grounded Theory, Fuzzy Delphi, Performance Measurement, Human Resource Efficiency

\section{Introduction}

The purpose of all organizations is to promote productivity in all organizational inputs. Enhancing productivity will also be realized due to the increased efficiency and effectiveness of the joint venture.

The Organization for the Economic Co-operation and Development (OECD) has defined productivity as resource sharing. The European Productivity Agency (EPA) defines productivity in two ways:

- Productivity is the maximum use of resources in production.

- Productivity is a kind of thinking: we must believe that what can be done tomorrow may be done better today (Haghighatian and Ezati, 2015).

According to Japan Productivity Center (JPC), productivity is a national priority and choice and any effort to increase productivity should lead toincreased social welfare, reduced poverty, and choose and perform the proper task. In other words, productivity means the scientific use of national resources like human resources and other factors of production in lowering prices, increasing market value, reducing unemployment, increasing real incomes, and increasing living standards of customers, managers and employees (Organization of Asian Productivity, 2004).

Obviously, using valuable and proportional physical assets, mixed with efficient human resources will allow for the realization of planned organization goals and increased productivity. 
Sometimes it is proven by experience and observation in various organizations that even the existence of great physical and capital assets, despite the valuable technical knowledge, has been devastated by inefficient, poorly functioning human resources and erosion of resources.

In other words, the realization and reaching the maximum productivity of other organizational inputs does not significantly correlate with the performance of human resources and the type of employee exposure to these inputs and resources.

Knowledge capital of the employees is one of the most significant components of organizational performance. However, for the proper functioning of the organization, the existence of knowledge is necessary and not enough - the human resources in an organization increase the use of tangible assets (tools and equipment) and use intangible assets (Fitz-enz, 2001).

The above concept brings about an increase in productivity and the increase in productivity and human resource performance leads to increased satisfaction of corporate executives. This satisfaction can end in more facilities, more welfare facilities, and development of assets, wealth and savings.

Accordingly, particular attention has been paid to the role of human resources in organizations compared to other sources of the company in recent years, and the researchers try to examine the factors and elements that increase the efficiency of human force.

Managing an organization to create an effective and empowered organization is just possible through the focus on education, boost creativity and initiative, raise morale, motivation, employee personality development, and so on. In order to reach these goals, in the first stage, the performance of the employees should be properly evaluated and examined, and after identifying the strengths and weaknesses of the employees in the above areas, the weaknesses and strengths should be addressed (Morgan \& Hunt, 2007).

A performance evaluation system was initially introduced at the individual and organizational level since 1800 by Robert Owen in Scotland in the textile industry. Thus, the products were graded using wood in different colors, and this was in fact a kind of quality evaluation or production of the organization (Housmand, 2012).

EPEprocess was developed in the early 20th century in the United States along withthe development of large businesses.

In Iran, the issue of performance evaluation dates back to the early seventh century AH. Khaje Rashid al-Din Fazlollah has been as the minister of Mogul government for more than 20 years and was the founder of the performance evaluation system in Iran in his innovative style in the classical form. However, later, the performance evaluation system appeared in government organizations in 1970. The pattern of this organization was similar to that of the army. In doing so, the Center for of the Evaluation of Governmental Organizations was established in Iran for the first time.

\section{Problem Statement}

Extracting a model as a checklist to evaluate and measure the employees periodically

\section{Literature review}

The start of this study, like most research studies, was with library studies and examining the scientific papers. A major part of the use of this section was to elaboratethe criteria for EPE.

As the selection criteria for human resources and the evaluation of the human resources performance are remarkably similar, they were also studied in library studies on the selection criteria for employees.

Using grounded theory, Dehkordi and Ebrahami (2016) analyzed the role of performance evaluation in organizational productivity. The study results showed that "Creativity, development of innovation and education, adherence to organizational commitments and principles, improvement of organizational communication, increase of rewards and benefits as the most significant components affecting performance evaluation, increase job satisfaction, attracting customers, employee survival, quality of service delivery and, finally, improvement of organizational efficiency."

Safari et al. (2016) examined the adequacy of employee selection and selective criteria in a study on organizational performance measurement. The study emphasized that human resources and employee competence are more important to the organization than other sources, and states that targeted employee selection is tangible in reducing, controlling the negative costs involved in obtaining wrong decisions, and training costs have a positive effect on increasing competitive ability and performance of the organization in the future. 
In a study on the relationship between performance evaluation and productivity in the organization, Haghighatian and Ezati (2015) explained the variables with a direct and significant relationship with productivity as follows:

The personal relationship of education, knowledge and skills, interests, wage and salary, work experience and willingness to work using proper methods of punishment and encouragement by managers, the participation rate in decision making, the existence of standard evaluation indices, intimate relationship of the managers, job security, freedom of action and independence

By developing a model for selecting employees based on the Islamic model of progress, Poursaeidi and Ashouri (2014) have considered religious, political, family, ethical and specialized qualifications as essential.

In examining the factors affecting the empowerment of employees for increasing organizational productivity, Aqdasi and Norouzzadeh (2013) considered the following factors as the most important and effective ones:

Collaborative management, having transparent goals, data and information provision, access to resources, reward system, authority delegation and EPE

By relying on two concepts of management and knowledge simultaneously, Agarwal (2013) described skills and technical knowledge, skills and knowledge of technology management, business skills and knowledge and managerial and inter-personal skills as the main criteria for selecting workforce.

Bast et al. (2012) identified the characteristics and specifications of the needed human resources in the selection process, including the ability to provide quality services, teamwork, communication skills, learning ability, management skills and leadership, and supporting the organizational values and goals.

Habibi and Zabeti (2011) examined and identified the factors affecting the improvement of human resources and the specific components of each of them, ending in the effect of performance evaluation on motivation, satisfaction, and willingness to educate and retain employees.

Leen (2010) argues that professional skills, background and previous professional occupation, achievements, and personality and ultimate strength are the critical features for the selection of the workforce.

Chitsaz et al. (2012) consider self-awareness, alertness, cultural entrepreneurship, communication, executive management, leadership, and Islamic values as the central determinants of recruitment.

Saadat Khoshouei et al. (2012) identified the values of skills, analytical skills, decision-making skills, knowledge-orientation, compatibility and adaptability, performance competency, leadership competence, and communication as essential criteria.

\section{Methodology:}

The study was descriptive and statistical analysis using grounded concept, fuzzy Delphi method, and survey method.

SPSS was used to analyze the statistical data.

Cronbach's alpha coefficient was used to measure the reliability of the questionnaire.

\section{Extracting performance evaluation criteria:}

As stated in the previous sections, the grounded concept and fuzzy Delphi method were used to formulate a performance evaluation checklist.

Firstly, using the grounded concept, the employees' performance measures criteria were collected and then by the fuzzy Delphi method, the final criteria agreed upon by the general experts were presented as the final checklist.

Upon introducing and describing the two applied methods of grounded concept and fuzzy Delphi method, we mention how to use these two tools.

\subsection{The grounded concept:}

The grounded concept of conceptualization is a method aimed at understanding the experiences of individuals from events in a particular context. The grounded-concept conceptualization theory is an inductive method of discovery, allowing the researcher to develop a theoretical account of the general characteristics of the subject while simultaneously consolidating the base of this report in empirical observations of data (Goldkuhl\&Cronholm, 2010). 
Grounded theory is an exploratory research method allowing the researcher to work on a new hypothesis in cases where it is impossible to formulate a hypothesis, instead of using its predefined hypotheses. In other words, the grounded theory is a method for gaining an understanding of the subject matter under study: a subject or subjects not thoroughly investigated before, and our knowledge is limited in this field (Ghaffarian and DehghaniPoudeh, 2006).

According to the implementation process of the grounded theory (Dehkordi and Ebrahimi, 2016), the following process of extracting the criteria affecting the performance of employees was carried out:

1- Starting the research by presenting a research question

2- Collecting data with analysis until reaching saturation

3- Analysis of the collected data

4- Presenting the hypothesis

-Data coding (Finding concepts) including open coding / axial coding / selective coding

Main question: What are the factors affecting human resource performance ultimately causing relative individual, colleagues, clients, and ultimately the managers' satisfaction?

The following resources were used for initial input for collecting the primary model of performance evaluation criteria:

- Reasons for leaving job or dismissing the personnel during a one-year period

According to the calculation of human resources indices, the information shows that over $70 \%$ of the workforce has fallen over a one-year period. In some key administrative-executive units, the average survival of the work force was estimated to be less than one month (about 20 days).

- Previous studies and the ones conducted by researchers from the field of management and human resources over the past years in this regard, some of which explicitly referred to the criteria affecting human resources performance.

- Reviewing the responsibilities of the various posts of the organization

- Relative and approximate comparison of status of employees with job satisfaction

- Studying EPE system in other units and organizations

- Using the results of the staff performance ratings, conducted experimentally using the general VisekriterijumskaOptimizacijaKompromisnoResenje (VIKOR) and Elimination et Choice Translating Reality (ELECTRE) criteria during the pre-run period, the results were consistent with the general expectations of the organization.

The results of the above axes, inputs for the foundation data approach, were used to extract the factors affecting human resource performance.

According to the analysis of the results from the above-mentioned axes, the human resources performance was first categorized into two general and specialized sections. Four areas of ethics and professional behavior, the field of creative thinking, innovation and initiative, the field of education and knowledge management and experience, and ultimately the field of satisfaction and general motivationwere identified as the main axes affecting the general performance of a working person.

These axes were given to 17 experts and after the agreement reached by 12 of them, their use was ensured. Other members of the experts who were invited to this process did not continue to participate.

Through a general agreement, the specialized function was considered as the only factor affecting the performance of the individual in terms of the success of the individual in the performance of the duties and responsibilities of the occupation communicated to him by the workplace or the employer.

In other words, these factors were seen as a response to the first stage of the question of this section of the study.

Figure 1 shows this relationship schematically. 


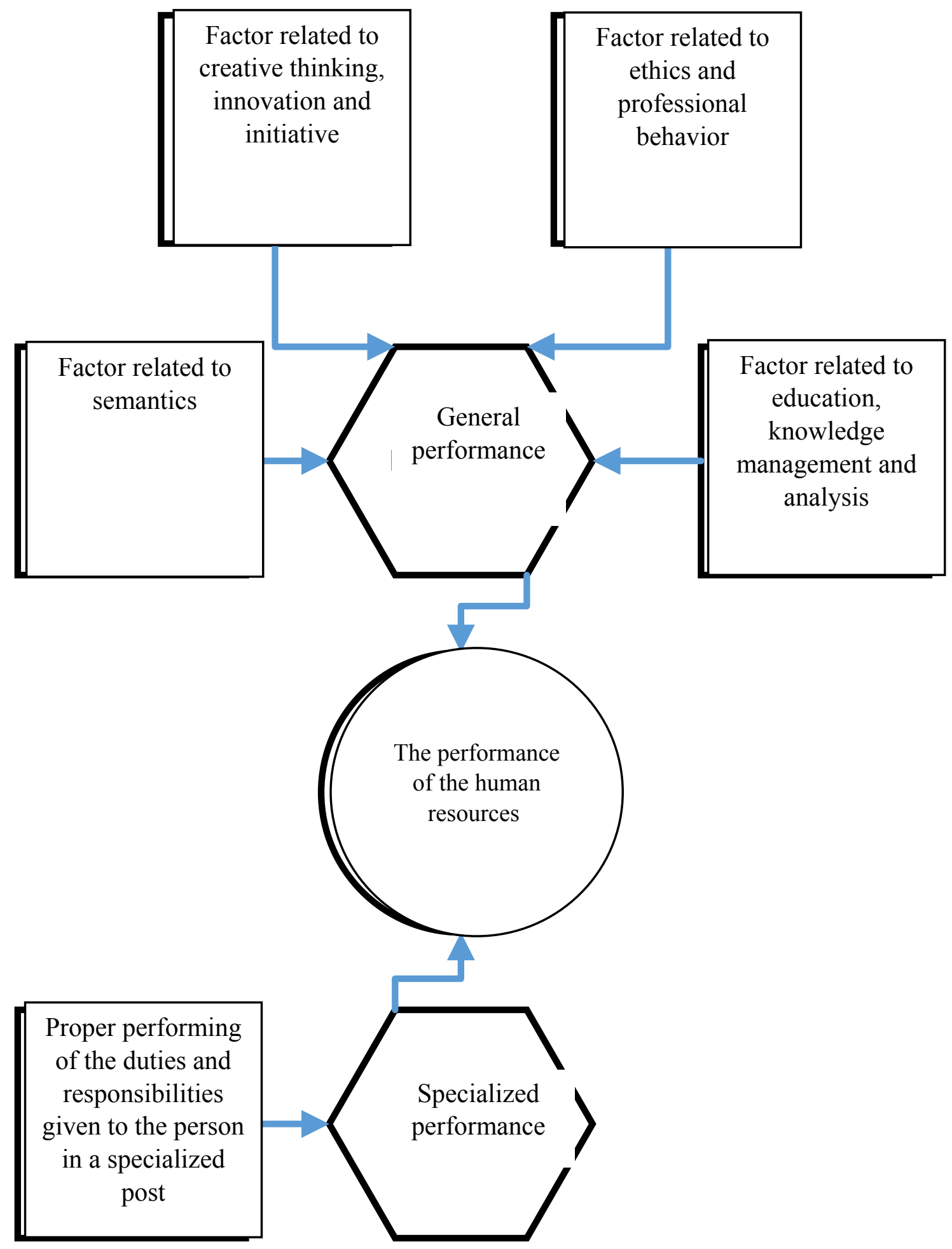

Figure 1: Factors Affecting Human-Resources performance

After that, the analysis was continued by interviews with experts.

In this interview, the audience is asked to list and describe the factors that contribute to the improvement of human resource performance. 


\begin{tabular}{|c|c|c|c|}
\hline \multicolumn{4}{|c|}{ Table 1: Open Coding Questions } \\
\hline Row & Performance type & $\begin{array}{l}\text { The area of primary effective } \\
\text { factors }\end{array}$ & Question for open coding \\
\hline 1 & \multirow{5}{*}{ Public performance } & $\begin{array}{l}\text { The field of ethics and } \\
\text { professional behavior }\end{array}$ & $\begin{array}{l}\text { What factors in the field of ethics } \\
\text { and professional behavior you know } \\
\text { that can affect the performance of } \\
\text { the individual? }\end{array}$ \\
\hline 2 & & $\begin{array}{l}\text { The field of creative and } \\
\text { innovation and initiative thinking }\end{array}$ & $\begin{array}{l}\text { What factors in the field of creative } \\
\text { thinking and innovation you know } \\
\text { that can affect the performance of } \\
\text { the individual? }\end{array}$ \\
\hline & & & \\
\hline 3 & & $\begin{array}{l}\text { The field of training and } \\
\text { managing knowledge and } \\
\text { experience }\end{array}$ & $\begin{array}{l}\text { What factors in the field of } \\
\text { education and knowledge } \\
\text { management and experience you } \\
\text { know that can affect the } \\
\text { performance of the individual? }\end{array}$ \\
\hline 4 & & The field of semantics & $\begin{array}{l}\text { What factors in the field of } \\
\text { semantics you know that can affect } \\
\text { the performance of the individual? }\end{array}$ \\
\hline 5 & $\begin{array}{l}\text { Specialized } \\
\text { performance }\end{array}$ & $\begin{array}{l}\text { Proper completion of the duties } \\
\text { and responsibilities conveyed and } \\
\text { the proper use of delegated } \\
\text { authority }\end{array}$ & $\begin{array}{l}\text { What should be done by a person to } \\
\text { conduct his duties and } \\
\text { responsibilities in a manner that best } \\
\text { suits his / her job position? }\end{array}$ \\
\hline
\end{tabular}

After obtaining the results by extracting the evidences in each report and categorizing them, the above axes were extracted.

The results of these questions make the base for open coding. In open coding, the selectable mode is not limited, and it is tried to assign the topics and related threads in a code.

The results of open coding are presented below.

General performance:

1) The field of ethics and professional conduct:

1.1. Commitment to the proper performance of duties, providing an effective response to assigned obligations and responsibilities, responsible for the proper implementation of assigned affairs, and monitoring the proper performance of the duties of subordinate staff, commitment to executive programs of the organization, not doing the task with commitment, and having conscientiousness.

1.2. The ability to work in several occupations, agility and high understanding in job placement, multidimensionality of worker character, succession power in the related colleagues tasks.

1.3. Sufficient trust in the accuracy of their performance, positive fighter morale, insistence on their work positions, lack of retreat in negotiations and conflicts, self-confidence and optimal personality capacity, selfconfidence

1.4. Self-reliance, the power to solve problems and making decisions independently, independence from manager decisions, independent decision-making insight, the power to manage their affairs without repeated referrals to related individuals, the ability to make quick decision-making in various situations

1.5. Cooperation spirit, work partnership, disability, teamwork ability, having constructive engagement, teamwork flexibility, and coordinated movement in teamwork 
1.6. A spirit of flexibility, lack of stress in the workplace, lack of superiority spirit, having a working environment, a spirit of healthy competition, consistent with colleagues, flexibility in labor relations and asking tasks from other employees

2) The area of creative thinking, innovation, and initiative:

2.1. The ability to prioritize, the power of staging different tasks and projects, the ability to recognize the importance of different stages of the work and the separation of its stages, so that the maximum efficiency is reached

2.2. Management of tasks division, ability to distribute resources equitably, correct and scientific analysis of work in the most efficient way.

2.3. Providing user suggestions, identifying improvement opportunities, having a critical thinking, having an audit view, introducing workplace productivity strategies, participating in a suggestion system, and presenting the application for continuous improvement.

2.4. The desire to update, follow the new methods, daring to identify and navigate new solutions have new ideas and thoughts

2.5. Identifying and discovering new tools at work, the lack of unwitting following from old solutions

3) Field of management and knowledge

3.1. The ability to teach occupational skills to others, including apprenticeship training, and the belief in the concept of learner organization

3.2. Having enough knowledge, continuous knowledge enhancement, regular and effective attendance at announced courses, using the learning at work, caring about teaching, the belief in continuous education and gaining awareness

3.3. Participation in educational design, such as precise need metrics, educational pamphlets, educational films, and so on, commitment to maintaining the learning in the organization and its use

\section{4) The field of semantics:}

4.1. Belief and respect for religious sanctities, observance of the principles of covering, observance of religious practices, enjoyment of dignity and privacy in the workplace

4.2. Adherence to religious and Islamic considerations, observance of participation in religious programs, enjoyment of Islamic education at work, attending a company in accordance with the organization's work schedule, observing the principles of health and safety at work, observing the rules and regulations of the organization's rules, motivating colleagues, and sharing useful and targeted information with other colleagues.

4.5. Timely attendance at meetings, timely performance of assigned tasks, such as managerial communications, approvals of meetings and so on, the power of reasoning and discussion, sharing thoughts and ideas, and working problems with other colleagues to explore solutions, explicit expressing of opinions, the power and ability of others to be fair and open, and having a critical attitude.

6.4. Trust, secrecy and security of information, and commitment to maintain the company's intangible assets

4.7. Respect for organizational hierarchy, sense of responsibility towards superiors, loyalty to the manager, having a sense of constructive and informed citizenship, adherence to and commitment to the objectives of the work unit, negotiation with unit management, commitment to promotion and enhancement of the indices of the job performance unit.

\subsection{The ability to analyze reports}

Specialized function:

1) Relative domination of job-related software at least at the level of professional qualifications, mastery and knowledge of how tasks are done, having lateral information that performs tasks better and faster, awareness of the principles of proper work, high-level academic education or courses related to the job, full knowledge of the duties and responsibilities

2) Effective experience in performing tasks, the ability to transform knowledge into objective performance, the power to implement the correct, safe and efficient working procedures announced 
3) Creating a sense of relaxation and job satisfaction in self and colleagues, the spirit of healthy competition, the desire for improvement and career advancement, the avoidance of daily work in the workplace, having a culture of ethical protest and providing timely feedback on work the environment

4) Transfer of empirical learning to other colleagues, recording new events in line with knowledge management, using past work record in solving problems of specialized areas, the ability to transfer and receive information quickly for optimal performance of tasks.

5) The proper conducting of the subordinate forces, the ability to solve the crisis in the area of duties and powers, the power of aggregation of resources for discovering the path and new strategies for better performance of duties

Axial coding is done after this stage. In axial coding, the process of assigning code to the concepts in the data is completely out of the open and takes the selective form. Indeed, after open coding, the researcher can identify the main axes in the dataset and do the next step in encoding around these axes (Mansourian, 2006).

In the last coding stage, known as selective coding, regarding the codes and concepts identified in the two previous steps, the researcher encodes the coding process more robustly and stresses the parts that can have a significant role in compiling the theory help facilitate the next steps (Mansourian, 2006).

In axial and selective coding, the relationships between the extracted themes are specified in the previous step. In the previous steps, each of the cases was analyzed separately and the related codes and themes were extracted. However, in this stage, the extracted codes and themes are examined simultaneously (Dehkordi and Ebrahimi, 2016).

According to the axial coding, the following themes are extracted:

\begin{tabular}{|c|c|}
\hline \multicolumn{2}{|c|}{ Table 2: Issues extracted by axial coding, the field of ethics and professional behavior } \\
\hline \multicolumn{2}{|c|}{ The field of ethics and professional behavior } \\
\hline 1 & Being multi task in the occupation and organization \\
\hline 2 & Having adequate and practical self-confidence \\
\hline 3 & Self-management and the power to manage business affairs \\
\hline 4 & Sense of partnership and belief in teamwork \\
\hline 5 & Suitable and logical adaptability and flexibility in the work environment \\
\hline 6 &
\end{tabular}

\begin{tabular}{|c|c|}
\hline \multicolumn{2}{|c|}{ Table 3: Extracted themes by axial coding - the field of innovative thinking, innovation, and initiative } \\
\hline \multicolumn{2}{|c|}{ Innovative thinking, innovation, and initiative } \\
\hline 1 & Planning and prioritizing affairs \\
\hline 2 & Breakdown and division of labor and resources \\
\hline 3 & Providing improving suggestions \\
\hline 4 & An innovative approach to problem solving \\
\hline 5 & Using new technologies / innovative techniques in performing tasks \\
\hline
\end{tabular}




\begin{tabular}{|l|l|}
\hline \multicolumn{2}{|c|}{ The field of training and managing knowledge and experience } \\
\hline 1 & \multicolumn{1}{|c|}{ Observing ethical and religious rituals and morals } \\
\hline 2 & \multicolumn{1}{|c|}{ Faith and virtue } \\
\hline 3 & \multicolumn{1}{|c|}{ Table 5: Themes extracted using axial coding - the field of semantics } \\
\hline & \multicolumn{1}{|c|}{ The field of training and managing knowledge and experience } \\
\hline 1 & Observing ethical and religious rituals and morals \\
\hline 2 & Faith and virtue \\
\hline 3 & Respect for career discipline, orderliness and adornment \\
\hline 4 & Collaboration with other colleagues \\
\hline 5 & The power of discourse, discussion and follow-up \\
\hline 6 & $\begin{array}{l}\text { Trust, Confidentiality and Commitment to Security of Property and Information and Organization } \\
\text { Purposes }\end{array}$ \\
\hline
\end{tabular}

\begin{tabular}{|c|c|}
\hline \multicolumn{2}{|c|}{ Table 6: Themes extracted using axial coding - specialized performance fields } \\
\hline The field of expertise involves performing optimal tasks and the proper use of powers \\
\hline 1 & Knowledge \\
\hline 2 & Skill \\
\hline 3 & Motivation \\
\hline 4 & Transferring experience \\
\hline 5 & Leadership \\
\hline
\end{tabular}

Hence, for the general part, 22 criteria and for the specialized part, 5 criteria for the primary model were collected and sent to the experts following the initial justification for consistency.

The proposed framework of the factors affecting employee performance is shown in Figure 2 according to the tables above.

Later on, using Fuzzy Delphi method, the extracted primary pattern was compared to the identification of the criteria selected by the consensus to develop EPEchecklist. 


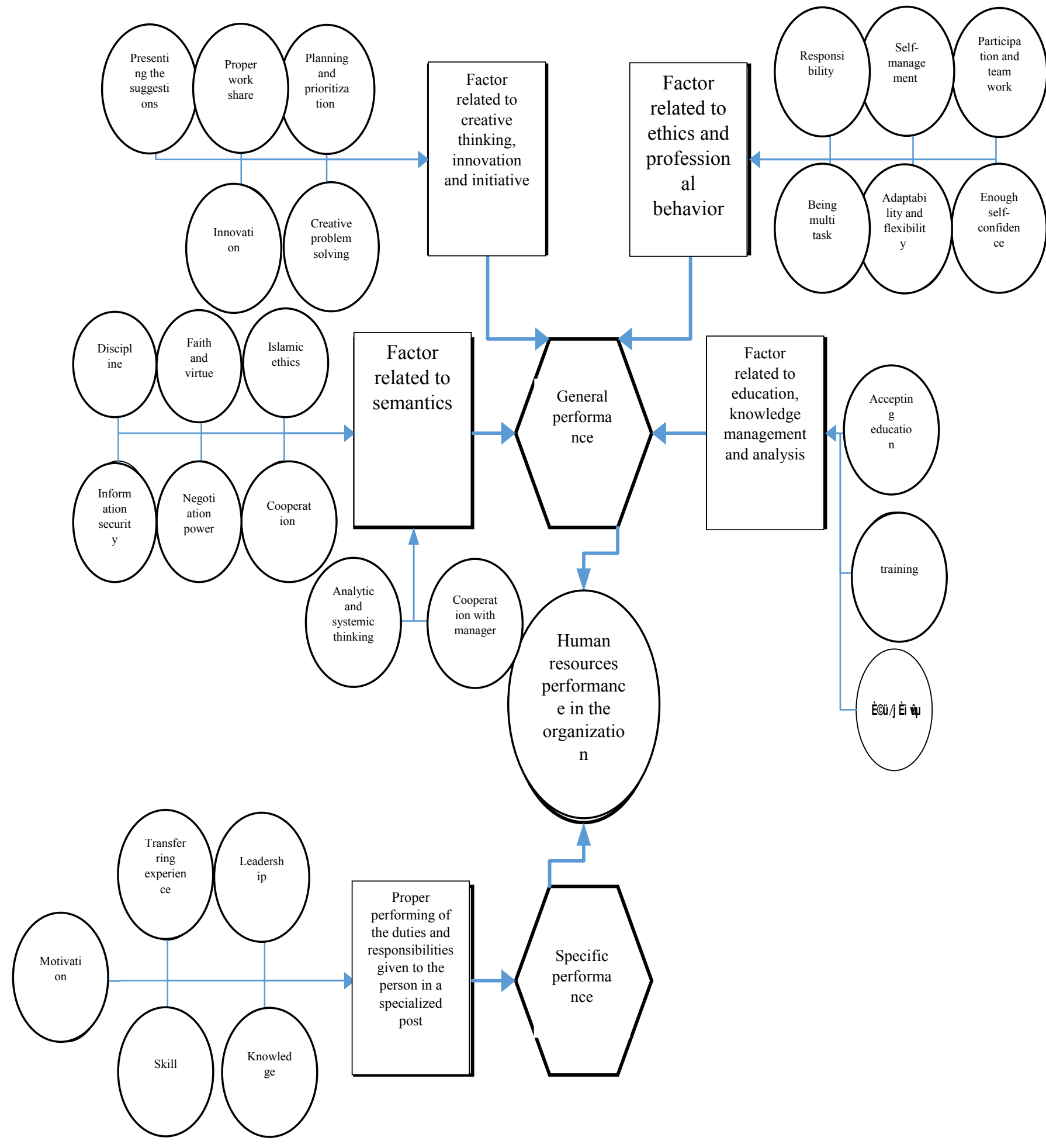

Chart 2: Sub-components of the factors affecting human resource performance

\subsection{Fuzzy Delphi Method:}

Fuzzy Delphi method was developed by Kaufman and Gupta in 1988 (Lew, 2002).

Fuzzy Delphi method is a combination of the traditional Delphi method and Fuzzy theory and is a kind of generalization of the traditional Delphi method in management (Safari et al., 2015). In the Fuzzy Delphi method, the necessary information is gained in the natural language of the experts and analyzed in a fuzzy manner (Kafashpour\& Alizadeh Zovarm, 2012). 
In his book, Multifactor Decision Making,Ataei (2009) describes the purpose of Fuzzy Delphi method: access to the most reliable collective agreement of the experts on a particular topic, done using the questionnaire for frequent surveying expert opinion, according to the feedback from them. In Fuzzy Management Science, Azar and Faraji (2002) believe that this method completely examines the opinions of the experts, with three main characteristics:

- Unbiased answer to questions (questionnaire)

- Repeating the number of the times asking questions (questionnaires) and receiving feedback from them

- Statistical analysis of the answers to the questions as group

The feature of this method is providing a flexible framework able to cover a wide range of inaccuracies and openness barriers. Many of the problems in decision-making are related to incomplete and inaccurate information. Moreover, the decisions made by the experts are based on their personal taste and are highly subjective. Hence, it is better to show data with fuzzy numbers instead of absolute numbers and be used in fuzzy sets to analyze experts' opinions (Tavakoli et al., 2013).

In Fuzzy Delphi method, the experts' team, first, identifies individuals and experts aware of the research subject matter.

Then, the research subject is explained to the team of experts and the necessary justifications are made in this regard.

The questionnaire or basic research questions are sent to experts in line with Delphi conditions and their views are taken in the form of qualitative concepts and quantitatively using fuzzy numbers.

According to the quantitative numbers assignments, averaging is done and the difference in the number of people is estimated with the calculated average separately.

The calculated difference with the average is sent to each expert for new ideas, and each expert will record and re-submit his new comments according to the results from the previous stage.

The average calculation and estimation of the average difference between each stage of the interview with the next stage is repeated and the process continues until the average of the fuzzy numbers is sufficiently stable. In other words, the average of opinions at each stage is with a low and acceptable difference compared to the average of the previous step.

In some studies, a limit is considered for each question to be accepted or not. In this study, the limit 0.8 was considered as the acceptable limit for the initial selection of each criterion at each stage of the interview. This means that at each stage of the interview, after calculating the definite numbers (deffuzified), the corresponding criterion is accepted at the first time stage to enter the next round of the interview if the definite number is equal to or greater than 0.75 . In fact, the coverage of the condition set means that the opinion of the majority of experts is to maintain that option or criterion in the questionnaire (Clemence \&Ascona, 2010).

Moreover, one can use a higher level for the desirable options / criteria and excellent levels.

If the definite (deffuzified) number is less than the acceptable limit, the questionnaire will be deleted and the corrected and screened questionnaire will be repeated in the next round of interview for the experts, along announcing the difference of points with the average of the previous stage will be sent to adopt a new opinion and consultation.

Additionally, the limit 0.2 is specified as the maximum acceptable value for comparing the mean difference in expert opinion in the various stages of the interview. In other words, if the difference in the mean score of a criterion or option in two successive stages of the interview is less than 0.2 , that criterion is acceptable. Thus, the repetition of the interviews by the experts is done as long as this mean difference for all options or criteria is all less than 0.2. In such a case, where the ideas of the experts have consensus: 


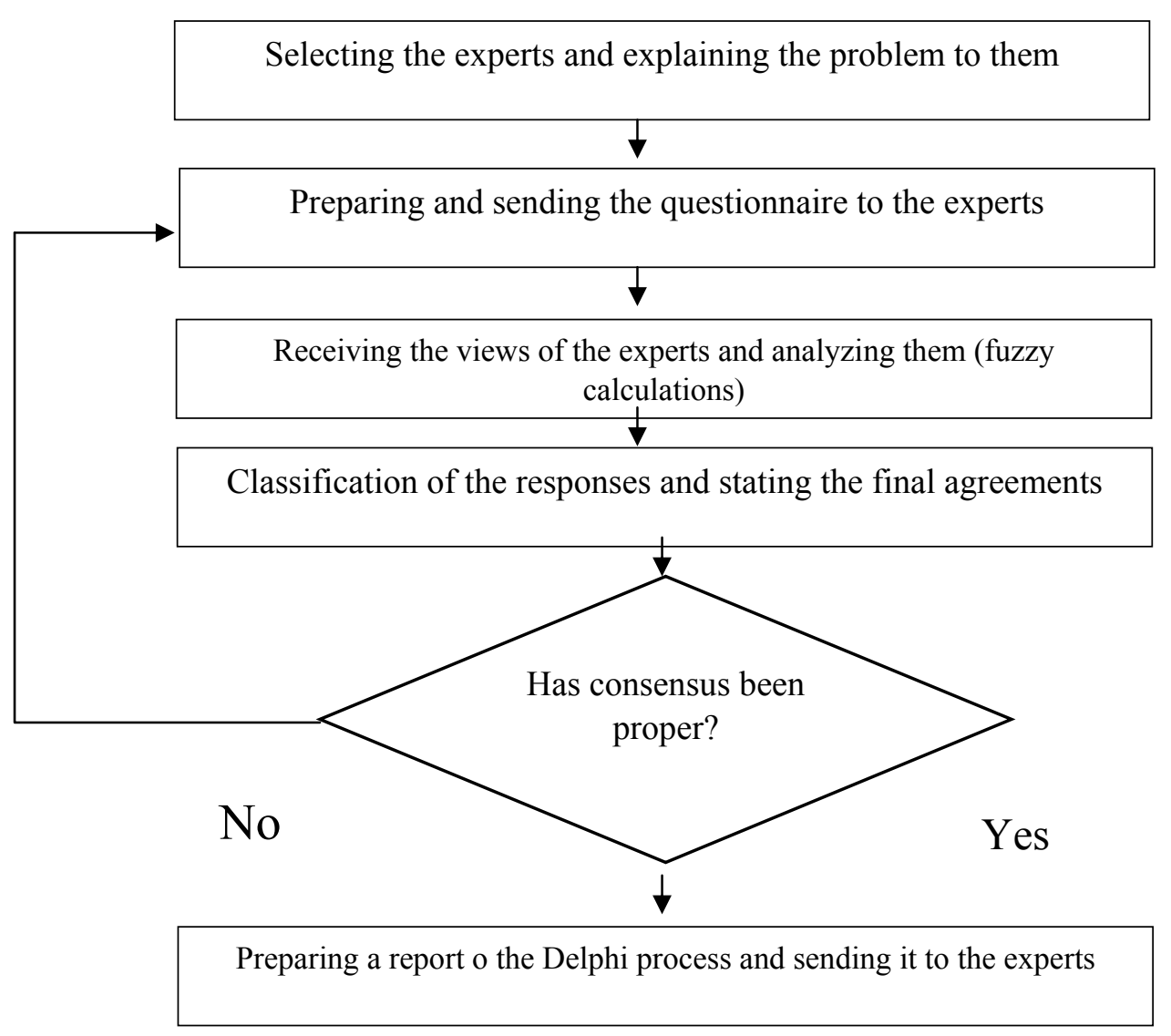

In Delphi method, the predictions presented by experts are stated in the form of definite numbers, but using definite numbers for long-term predictions distances the predictive outcome from reality. Moreover, expert people use their mental capabilities to predict, showing that the uncertainty governing these conditions is possible rather than probable. The uncertainty being possible is compatible with fuzzy sets and it is better to use long-term prediction and real-world decision making using fuzzy sets (using fuzzy numbers) (Ataei, 2009).

In other words, sometimes using explicit numbers in decision making for such cases is so tough and impractical, so fuzzy numbers are used (Ahadi and Ghazanfarizadeh, 2011). Reviewing the previous studies shows that fuzzy numbers are efficient and useful tools for modeling a system in conditions of uncertainty and lack of trust in the accuracy of data.

\subsubsection{Fuzzy numbers:}

At this stage, fuzzy numbers can be calculated according to different membership functions like triangular or trapezoid methods. Finally, it is determined based on the linguistic word of the experts.

Calculating triangular fuzzy numbers is shown in Figure 4. In this mode, a triangular fuzzy number is calculated using the following equations (Liu \& Chen, 2007):

The study used the geometric mean (Yuan, Claire, 1995) to find the idea of experts on a criterion. It is assumed that the value of the evaluation of criterion $\mathrm{j}$ from the iexpert's view from among $\mathrm{n}$ expert is $\mathrm{Wij}=(\mathrm{aij}, \mathrm{bij}, \mathrm{cij})$, where $\mathrm{j}$ is equal to $\mathrm{j}=1,2,3,4, \ldots, \mathrm{m}$ and $i$ is equal to $\mathrm{i}=1,2,3,4, \ldots, \mathrm{n}$. Therefore, the fuzzy value of the criterion $\mathrm{j}$ is calculated from Equations 1 to 3 :

$$
\begin{aligned}
\mathrm{a}_{\mathrm{j}}=\operatorname{Min}\left\{\mathrm{a}_{\mathrm{ij}}\right\} & \text { Equation (1) } \\
\mathrm{b}_{\mathrm{j}}=1 / \mathrm{n}\left\{\sum \mathrm{b}_{\mathrm{ij}}\right\} & \text { Equation (2) } \\
\mathrm{c}_{\mathrm{j}}=\operatorname{Max}\left\{\mathrm{c}_{\mathrm{ij}}\right\} & \text { Equation (3) }
\end{aligned}
$$


We use Equation 4 for the defuzzification.

$$
\text { Equation 4: }
$$

$$
\mathrm{S}_{\mathrm{j}}=\left(\mathrm{a}_{\mathrm{j}}+4 \mathrm{~b}_{\mathrm{j}}+\mathrm{c}_{\mathrm{j}}\right) / 6 \quad \mathrm{j}=1,2,3,4, \ldots, \mathrm{m}
$$

Finally, we consider a limit for extracting the desired criterion, and consider its being accepted or not at each stage. To accept the criterion remaining, the numbered phase must be equal to or greater than that limit.

$\alpha \geq \mathrm{Sj}$ : The criterion is accepted

$\alpha<\mathrm{Sj}$ : the criterion is eliminated

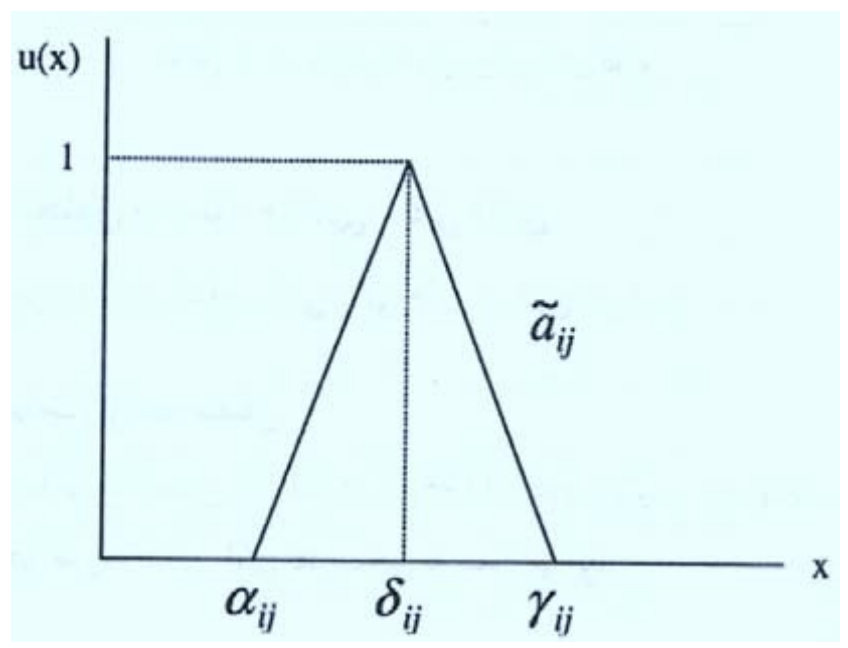

Figure 4: Triangular membership function in fuzzy Delphi method

\subsubsection{Selecting the experts:}

One has to consider some criteria for selecting the right people and the right number in selecting the experts. As one of the prominent scholars in methodology, Grisham (2009) says, "What is significant in selecting individuals is answering the questions without bias, their interest in the topic or title, and more important is their sufficient knowledge about the subject."

In some studies, a maximum of 60 people, and in others, minimum of 15 are considered as the experts (Grisham, 2009).

In the present study, 17 people were selected as experts according to the conditions. The initial model of performance measurement criteria; i.e., the first questionnaire, was sent to selected experts. They were asked to rate the significance of each criterion in the form of a Likert spectrum - as very low, low, average, important, and very important - and return their ideas. Out of this number, 12 respondents completed their questionnaires and returned them in the first round. Thus, continuing the routine was with 12 experts.

In this study, triangular fuzzy numbers were used given their extensive use and ease of calculating this method. Fuzzy numbers were assigned to the quantitative values for the conversion of qualitative options as follows:

\begin{tabular}{|c|c|c|}
\hline Row & Description & Triangular fuzzy numbers \\
\hline 1 & Very important & $(1,1,0.75)$ \\
\hline 2 & Important & $(1,0.75,0.5)$ \\
\hline 3 & Average importance & $(0.75,0.5,0.25)$ \\
\hline 4 & Low importance & $(0.25,0)$ \\
\hline 5 & Very low importance & $(0,0)$ \\
\hline
\end{tabular}

According to the results of deffuzified numbers, each criterion does not cover the specified parameters below 0.8 or $80 \%$ for retention in the questionnaire. 


\begin{tabular}{|c|c|c|}
\hline \multicolumn{2}{|c|}{ Table 7: Deleted criteria in the first period of the performance evaluation questionnaire } \\
\hline Row & Criterion & $\begin{array}{c}\text { Definitive number } \\
\text { (Deffuzified) }\end{array}$ \\
\hline 3 & Having enough and practical self-confidence & 0.48 \\
\hline 16 & Faith and virtue & 0.45 \\
\hline 18 & Collaboration with other colleagues & 0.41 \\
\hline 27 & Leadership & 0.56 \\
\hline
\end{tabular}

Thus, the second phase of examining the questionnaire will continue with the remaining criteria. The results of the first stage are sent separately to each of the experts and getting the points is done again.

In collecting the second round of the results of the questionnaire, criteria 5 and 19 of the general checklist lack the required criteria, given the smaller definitive number (deffuzified), relative to the acceptable level ( 0.8 to $80 \%)$ and are eliminated.

As the difference in the average opinions of the experts in this period and the previous period was less than the limit set at 0.2 , the experts have reached a consensus and the process of the survey of experts' stops at the same stage and residual criteria are considered as the final criterion applicable to the performance evaluation checklist.

\section{Results:}

Thus, the final checklist of performance evaluation is used with holding training sessions in general and specialized sections and each section, with 17 and 4 criteria for streamlining in the compiling system and used for 164 employees in a controlled manner.

The reliability and validity of the questionnaire according to Cronbach's alpha coefficient was 95.2\%, which showed the validity and adequacy of the questionnaire.

Given the case study, stating the performance evaluation using a 360-degree method, efforts were made to use the measurable criteria from the main audience and recipients of the services.

\section{Conclusion}

One can monitor the level of employee performance using periodic implementation of human resources' performance evaluation checklist. Using the monitoring results, the extraction of the reasons for the loss of performance or the identification ways to enhance the level of performance, was possible. Thus, with the continuation of this process, one can anticipate that human resource productivity will be studied and controlled as well.

Given the need to respect Delphi principles regarding privacy and facilitating the provision of comments by the experts, implementing it required considerable time. Nonetheless, according to the consensus of experts in the sample, a combination of managers, industry experts and consultants, one can state that a large part of the key criteria has covered the managers and employees of an industrial unit.

Inthe next studies, one can evaluate and validate the criteria extracted from grounded theory using factor analysis and examine and compare the questionnaire extracted from the factor analysis with the present questionnaire during the implementation.

\section{Reference}

[1] Mohamad, M. Jais, J. Emotional Intelligence and Job Performance: A Study Among Malaysian Teachers, 7th International Economics \& Business Management Conference, 5th \& 6th October 2015, Procedia Economics and Finance 35: 674 - 682, 2016.

[2] Basogul, C. Ozgür, G. Role of Emotional Intelligence in Conflict Management Strategies of Nurses, Asian Nurs Res (Korean Soc Nurs Sci). Sep;10(3):228-233. doi: 10.1016/j.anr.2016.07.002. Epub 2016 Jul 19, 2016.

[3] Haghighatian, M., \& Ezati, Y. An Investigation into Effective Factors on Human Resources Productivity (Case Study: Region 11, Islamic Azad University, Iran). In: Procedia Social and Behavioral Sciences, 205, 601-607,2015.

[4] Aggarwal R. Selection of IT Personal through Hybrid Multi-attribute AHP-FLP approach, In: International Journal of Soft Computing and Engineering (IJSCE), 2(6), 11-17, 2013.

[5] Sadat Khoshouei, M., Oreyzi, H. R., Noori, A. The Eight Managerial Competencies: Essential Competencies for Twenty First Century Managers, In: Iranian Journal of Management Studies (IJMS), 6(2), 131-152, 2013.

[6] Bassett, M. L., Ramsey, W. P., \& Chan, C. C. Improving medical personnel selection and appointment processes, In: International Journal of Health Care Quality Assurance, 25(5), 442-452, 2012.

[7] Goldkuhl, G. \& Cronholm, S. Adding Theoretical Grounding to Grounded Theory: Toward Multi-Grounded Theory, In: International Journal of Qualitative Methods, 9(2), 187-205, 2010.

[8] Lin H. T. Personnel Selection using analytic network Proccess and Fuzy Data Envelopment Analysis Approaches, In: Computers \& Industrial Engineering, 59, pp. 937-944. 2010.

[9] Kelemenis, A. \& Askounis, D. A New Topsis-based multi-criteria Approach to Personnel Selection, In: Expert Systems with Applications, 37(3), 999-5008, 2010. 
[10] Grisham T . The Delphy technique, a method for testing complex and multifaceted topics, In: International Journal of Managing Projects in Business,2(1): 112-130. 2009.

[11] Byars, L.I \& Rue, L.W. Human Resource Management. 9 th Edition. New York: Mc GrawHill, 2008.

[12] Delucca, D. Performance Appraisal for at-will Employees, Personal Interviews, July 8-9, 2008.

[13] Morgan, R. M. \& Hunt, S.D.HRM: Conceptualization and Scale Development, European Journal of Marketing: Vol. 39 no. 11, pp. 1264-1290, 2007.

[14] Wu, W.-W., \& Lee, Y.-T. Developing global managers' competencies using the fuzzy DEMATEL method. Expert Systems with Applications, 32, 499-507,2007.

[15] Francesco, A.M.and B. A. Gold. International Organizational Behavior: Text, Cases, and Skills, 2nd edition. Upper Saddle River, New Jersey: Pearson Prentice Hall, 2005.

[16] Ivancevich, J. M. Human Resource Management, (9th edition), McGraw Hill/Irwin Companies, New York, 255-287,2004.

[17] Newton, L., \& Schmidt, D. Wake-up Call, Thomson South-Western, Mason, OH, 2004.

[18] Loo, R. The Delphy Method: A Powerful Tool Strategical Management, Policing An International Journal of Police Strategies \& Management, Vol. 25, No. 4, P. 762-769, 2002.

[19] Nakata, C. and K. Sivakumar, "Instituting the Marketing Concept in a Multinational Setting: The Role of NationalCulture," Journal of the Academy of Marketing Science, Vol. 29, 2001.

[20] Fitz-en, J, The Rol of Human Capital. New York: American Management Association, 298, 2001.

[21] McCarty M. Caravan T. 360 Feedback and Proccass: Performance Improvement and Employee Career Development, In: Journal of European Industrial Training, PP.5-3, 2001.

[22] Foot, M. \& Hook, C. Introducting Human Resource anagement. Longman, 1999.

[23] Carell M. R., and et al. (1992), Personnel Human Resource Management, Mac Millan Publishing.

[24] Casio, W., (1991), Applied Psychology in Personnel Management, (4th edition), Prentice-Hall, Upper Saddle River, NJ.

[25] Boyatzis, R. E. (1982). The Competent Manager: A Model for Effective Performance. John Wiley \& Sons. New York.

[26] Hofstede, (1980) G., Culture's Consequences, Sage, Beverly Hills

[27] Taylor, Edward. (1871). Primitive Culture. New York: J. P. Putnam's Sons.

[28] Saheb azamani, M., Farahani, H., Mehrbani, E., Shahbazi, M.Y., Investigating Validity and Reliability of Evaluation Based On 360 Degree Method In Clinical Evaluation of Nursing Students, Journal of Islamic Azad University of Medical Sciences, Winter 2017, Volume 26, Issue 4: Pages 264 to 270

[29] Ebrahimi, M., Mobini Dehkordi, E., Analyzing the Role of Performance Evaluation System in Organizational Productivity Using Grounded Data Theory. Journal of Human Resource Management Research, Imam Hussein University, Autumn 2016, Eighth Year, Number 3 (25): Pages 59-81.

[30] Behnamfar, R., Rasti, A., Linear regression, normality of the distribution of error values, or normality of the dependent variable? Iranian Journal of Education in Medical Sciences, 6,7 (33): pages 263-265.

[31] Samadi, R. Investigating The Effect of Emotional and Spiritual Intelligence on Job Performance of Iranian Oil Pipeline and Telecommunication Company Staff, Islamic Azad University - Science and Research Branch of Ayatollah Ali, Farsi Theses, 2015.

[32] Osouli Ghareh Aghaji, Sh., Sanayeiae, A., SaieadAbadi, M.R., Presentation of an Extended Model of the Impact of Electronic Culture Factor on Market Regulation and Pricing of Goods and Services, Modern Marketing Research Quarterly, Atumn 2016, Volume 6, Issue 3, Issue 22: Pages 53-66.

[33] Fathi Ashtiani, A., Dastani, M., Psychological tests - personality and mental health. Be'athat Publications., 2016

[34] Behzadi, H., EsmaieelZadeh, M. H., Investigating of The Status and Relationship between Social Intelligence and Job Performance of Managers of Astan Quds Razavi Libraries, Journal of Libraries and Information Science, 2015, Organization of Museums and Documentation Center of Astan Quds Razavi, Volume 18, Number4, (sequential 72): Pages 3-30.

[35] Safari, J., Mehdizadeh, M., Azizi, A. R., Designing a Model Based on Criteria for Selection of Employees and Estimating Organization Performance., Quarterly Journal of Human Resource Management Research Imam Hussein (AS),7 (4), pages 141-166, 2015.

[36] Poursaiead, S. M., Ashouri, J., Creating a Model for Personnel Selection Based on the Iranian Islamic Model of Progress, Human Resource Management Research, Imam Hussein University of Technology, Vol. 6, No 3, 1-25, 2014.

[37] Zrea, Z., Bakhtiary, R., Nourizadeh, M., Analyzing the Results of Al-Zahra University Staff Performance Evaluation in 2012, First Edition, Tehran, Azal Publications, Winter 2013.

[38] Tavakoli, H., Fayaz, M., Hasannezhad, M., Investigating the Performance of Rangeland Plans of Khorasan Razavi Province Using Fuzzy Delphi Approach and Multi-Criteria Decision Making Models, Journal of Economic and Agricultural Development, Spring 2013, Volume 27, Volume 1, Pages 37-50.

[39] Keyzouri, A. H., An Effective Employee Performance Assessment System; Foundations, Approaches and Methods, (PhD Thesis), Shahid Beheshti University, 2013.

[40] Aghdasi Anvari, S., Norouzzadeh, R., Factors Affecting Human Resources Empowerment. Journal of Human Resource Management Research, Imam Hussein University, 5 (1), pages 197-222, 2013

[41] Kaffashpour, A., Alizadeh Zavarem, A., Using of Fuzzy Delphi Analytical Hierarchy Process (FDAHP) and Hierarchical Cluster Analysis (HCA) in R model. F. Um. (RFM) to Determine the Value of a Customer Lifetime, Modern Marketing Research, Fall 2012, Volume 2, Issue 3, Number 6 (6) Pages: 51-68.

[42] Chitsaz, E., Zolfagharzadeh, M. M., Ghiasi Nadoushan, S., Developing a Model of Core Competencies for Cultural and Social Managers of Universities in Islamic Iran, Management in Islamic University 2, Summer 2012, Vol. 1, No. 2, Pages: 27-48.

[43] Amirzadeh Behbahani, R., Yaghoobi, Z., Evaluation of Staff Performance of National Iranian Oil Products Distribution Company of Ahvaz Region Using Analytical Hierarchy Process, Journal of Industrial Management, Faculty of Humanities, Islamic Azad University, Sanandaj Branch, Spring2012, Volume 7, Number 19, Pages: 97-107.

[44] Habibi, A., Zabet, M. R., Investigating the Impact of Performance Evaluation on Human Resources Improvement in Naja Headquarters. Pars Modir Research Journal, No. 1, pp. 111-122, 2012.

[45] Ahadi, H. R., Ghazanfari Rad, F., Presenting a Combined Model of Fuzzy Multi-Criteria Decision Making Methods for Locating a Specialized Railway Industrial Town, Journal of Operations Research and Its Applications, Winter2012, Eighth Year, Number 4 (31), Pages: $1-11$.

[46] Haghighi, M., Gharleghi, E., Mirasadi, S., A survey of relationship between the characteristics of mission statement and organizational performance (Case of: food industries in Tehran), Journal of Transformational Management, 2010, Volume 2, Number 4, 166-186.

[47] Golparvar, M., Khaksar, F., The Relationship between Emotional Intelligence and Job Performance of Isfahan Industrial City Factors. Daneshvar Research Quarterly Journal of Behavior, Clinical Psychology and Personality, Shahed University, May 2009, Volume 17, Number 40, pages 19-34, 2010. 
[48] Seyedi, S. M., Akbari, A. R., Performance Management and its Impact on Increasing Human Resource Productivity, Yadman Quarterly Journal, 2009, Yadman Structure Company, No. 53, p. 58.

[49] Rahnavard Ahan, F., Factors Influencing the Performance of Iranian Public Sector Organizations. Journal of Humanities and Social Sciences Management, Vol. 8, No. 4 (31 consecutive), 100-77, 2008.

[50] Hekmatnia, H., Moosavi, M. N., Factor Analysis and Integration of Indicators in Determining Factors Affecting Human Development of Iranian Areas. Journal of Geography and Development, pages 55-70, 2005.

[51] Asadi, j., Borjali, A., Jamhari, F., The Relationship between Emotional Intelligence, Job Burnout, and Mental Health of Iran Khodro Employees. Counseling News and Research, Volume 6, Number 22, pp. 41-56, 2005.

[52] Kalantari, Kh., Data processing and analysis in socio-economic research. Tehran, Sharif Publications, 2003.

[53] Azar, A., Faraji, H., Fuzzy Management Science, Iran Center for Productivity and Studies, 2008, Publications Society.

[54] Ahmadvand, M. A., Psychology of Exceptional Children, Tehran, , Payam Noor Publishingm, 1996.

[55] Fani, A. A., 360-degree feedback. Performance Evaluation / Development Management, Tadbir Monthly, No. 147, 2003.

[56] Rahnavard, F., Factors Influencing the Performance of Iranian Public Sector Organizations, Journal of Humanities and Social Sciences Management, Vol. 8, no. 4 (31 consecutive), 77-100.

[57] Performance Management and its Impact on Increasing Human Resource Productivity, Yadman Quarterly Journal, Tehran Yadman Sazeh Company, No. 53, pp: 53.

[58] Sa'atch, M., : Kamkari, K., Askarian, M., Psychological tests,Virayesh Publishing, 2010.

[59] Robbins, S. P., :Organization Theory: Structure, Design, and Applications, Alvani, M., DanaieaFard, H., Tehran, Safar Publications, First Edition, page 480., 2008,

[60] Ataiee, M., Fuzzy Multi-Criteria Decision Making, Book of Industrial Engineering, Second edition, Shahroud, Shahroud University of Technology Publications, February 2017.

[61] Danayieafard, H., Emami, M., Qualitative Research Strategies: Reflection on Fundamental Data Grounded Data Theory. Management Thought, 1 (21) Pages 69-97, 2007.

[62] Sarmad, Z., Bazargan, A., Hejazi, E., Methods in Research in Behavioral Sciences, Tehran, 2006, Nashr Agah Publications.

[63] Ghafarian, V., Dehghani Poudeh, H., Scientific theorizing in managerial studies and providing a hands-on experience. Management Research in Iran, 10, pp. 151-167, 2006.

[64] Mansouian, Y., Grounded Theory (Context Theory), Conference on Information Science Challenges at University of Isfahan, Comprehensive Management Site, 2006.

[65] Alvani, S. M., Public Management, Ney Publications, Tehran, 3th Edition.2015. 